\title{
Market Power in the Irish Beef Processing Industry
}

\author{
Rao Fu ${ }^{1, *}$, Chenguang $\mathrm{Li}^{1}$ and Liming Wang ${ }^{2,3}$ \\ 1 School of Agriculture and Food Science, University College Dublin, D04 V1W8 Dublin 4, Ireland; \\ chenguang.li@ucd.ie \\ 2 School of Economics and Management, Beijing University of Technology, Beijing 100124, China; \\ liming.wang@ucd.ie \\ 3 Irish Institute for Chinese Studies, University College Dublin, D04 V1W8 Dublin 4, Ireland \\ * Correspondence: fu.rao1@ucdconnect.ie
}

Citation: Fu, R.; Li, C.; Wang, L. Market Power in the Irish Beef Processing Industry. Sustainability 2021, 13, 6453. https://doi.org/ $10.3390 /$ su13116453

Academic Editor: Giuseppe Antonio Di Vita

Received: 28 April 2021

Accepted: 2 June 2021

Published: 6 June 2021

Publisher's Note: MDPI stays neutral with regard to jurisdictional claims in published maps and institutional affiliations.

Copyright: (c) 2021 by the authors. Licensee MDPI, Basel, Switzerland. This article is an open access article distributed under the terms and conditions of the Creative Commons Attribution (CC BY) license (https:// creativecommons.org/licenses/by/ $4.0 /)$.

\begin{abstract}
Irish beef processors and cattle farmers have been involved in a lasting controversy on power asymmetry. This paper estimates the degree of market power in the Irish beef processing industry. The New Empirical Industrial Organization approach is extended for estimation, and the market power is testified by conjectural elasticity with supply and demand functions, indicating that beef processors exert a significant market power on cattle farms. Export-orientation and high subsidies are two outstanding features in the Irish beef industry. Exports and subsidies are shown in this paper to have an insignificant influence on market power. This paper confirms that beef processors can exercise market power on farmers to lower prices below the marginal cost.
\end{abstract}

Keywords: market power; Irish beef; beef processing

\section{Introduction}

The Irish beef sector is Ireland's largest agricultural sector, involving over 100,000 beef farms. It is one of Ireland's most important indigenous industries and a vital part of the agri-food sector (Department of Agriculture Food and the Marine ('DAFM')). According to Bord Bia (the Irish Food Board), the total production of Irish beef was estimated as 624,000 tonnes in 2019 , valued at $€ 22$ billion. This accounted for about $56.68 \%$ of the combined value of Irish meat and livestock [1]. Furthermore, Ireland is the largest exporter of beef in the EU and the sixth-largest exporter of beef globally [2]. In 2019, beef exports (including offal) were valued at $€ 2.1$ billion [1]. Hence, the Irish beef sector plays a vital role in the Irish economy.

The Irish beef supply chain involves five main activities: farm inputs; farming; slaughtering and processing; branding, marketing, and distribution (in the beef sector, it refers to marketing campaigns to develop consumer brands and distribute products to retailers [3]); and sales and retail [2]. The Teagasc National Farm Survey (2019) indicated that nationally there are more than 50,000 farms involved in Irish cattle enterprises [4]. In 2019, there were approximately 25,455 cattle rearing farms, with an average of $€ 9188$ in annual income, and 28,239 other types of cattle farms, with an average of $€ 13,893$ in annual income. ('Cattle rearing farms' and 'cattle other farms' are referenced in the Teagasc National Farm Survey, where they are classified by Standard output (SO). 'Cattle Rearing' refers to an output equal to or greater than $50 \%$ of the SO from suckler cows. 'Cattle other' refers to an output less than $50 \%$ of the SO from suckler cows.) For cattle rearing farms, the gross output was $€ 36,715$ in 2019 , which was a $2 \%$ increase compared with 2018 , while the total costs, at $€ 27,527$, decreased by $1 \%$. The average farm size was 31.9 hectares with 36.7 livestock units. For other types of cattle farms, the gross output was $€ 50,470$ in 2019 , which was a $4 \%$ decrease compared to the previous year, while the total costs were $€ 36,577$, a decrease of $3 \%$. Farm size averaged 36.2 hectares and average total livestock decreased to 47.6 from 51. The average income level showed a decline in 2018 due to extreme weather, while there was a recovery in average family farm income (FFI) in 2019. However, the average 
income was still lower than that achieved in 2017, as low cattle prices caused a reduction in income. As a result, the direct payments contributed $129 \%$ to cattle other farms and $160 \%$ to cattle rearing farms [4]. This statistic indicates that farm income is highly reliant on direct payments rather than output income, which means that market returns are poor. The EU Common Agricultural Policy (CAP) was initially established to support the incomes of farmers, preserve the environment and encourage rural development. (According to DAFM, 'the CAP supports the development of the sector through a combination of direct payments to farmers, financial assistance towards investments in rural development and environmental protection and market support measures.') The basic payment scheme acts as a protector for farmers by amplifying their main business income supported by the EU's rural development 2014-2020 policy [5].

For beef processing, the data published by Bord Bia represents 30 registered beef processors and 58 plants which work mainly on beef slaughtering, cutting, further processing, and packing. The DAFM survey in 2015 shows that there were 32 major export-oriented privately-owned slaughtering facilities and 195 low-volume processors. The 30 DAFM approved plants account for $95 \%$ of the total slaughter, while the local-government-licensed abattoirs serving some of the domestic butchery trade account for $5 \%$ of the total slaughter [6]. The processors are highly concentrated and working below capacity. The big four Irish meat processors (ABP, Dunbia, Dawn, and Kepak) account for 65\% of the total Irish cattle slaughter and approximately 45\% of the UK slaughter [7]. Until May 2019, according to the IFA, the big three groups of ABP, Dawn, and Kepak had 65\% of the total beef processing market. In addition, the beef industry was recorded to slaughter 3 to 3.5 million animals annually, while the actual slaughter ranges from only 1.5 to 2 million per annum. The impact of this extra unused capacity is estimated to increase costs by between 12 and $15 \%$ [8].

Obviously, there is a big asymmetry between cattle farms and processors. The market return for farmers is poor, while the processors, in contrast, are highly concentrated and make huge profits. Moreover, market transparency is also a big issue. There are lots of very detailed information and articles regularly available on farm or cattle production in the Irish beef industry. On the contrary, there are fewer public data on processing. In 2019, there were tractor protests by farmers in central Dublin against the price of beef. The beef farmers were angry and frustrated at the price they were getting for their cattle, which suggests the profound contradiction between farmers and processors. It is clear that processing is highly concentrated, while competition is limited. However, the Competition and Consumer Protection Commission (CCPC) has stated that there is no evidence to suggest a cartel in the beef industry, while many farmers believe that there is collusion. Therefore, the purpose of this paper is to estimate whether beef processors might exercise market power on farmers by keeping cattle prices below a competitive level to gain profits for processors and thereby harming farmers' profits.

Strictly speaking, there is no modern agricultural market that meets the conditions for competitive markets. Sexton (2013) states that by studying market power issues, professionals try to understand the implications of improving product differentiation and vertical coordination on market performance and the distribution of benefits among firms and stakeholders [9]. Academic work has been applied to departures from perfect competition to evaluate the performance of agricultural markets. Since the 1980s, market power research has played a vital role in understanding agriculture and food production with a focus on the wheat, dairy, and meat sectors by adopting market power theories from the industrial organization field.

Market power is quite elusive in terms of an economic definition, with some economists also referring to similar terms such as monopoly power, oligopoly power, oligopsony power, or market control. Landes and Posner (1981) define the term 'market power' as the ability of a firm to raise prices above the competitive level without losing so many sales so rapidly that the price increase is unprofitable and must be rescinded' [10] (p. 931). The early studies applied the Structure-Conduct-Performance (SCP) paradigm to estimate market 
power [11,12].Later Bresnahan (1989) and Applebaum (1982) developed empirical models to estimate industry-level conduct parameters using industry-level data. These studies initiated the New Empirical Industrial Organization (NEIO), which has been widely applied by measuring conjectural variation parameters. It estimates the intensity of oligopoly power at the industry level. This approach has stronger theoretical foundations and uses more available data [13-15]. According to Perekhozhuk, Glauben, Grings, and Teuber (2017), the most important advantage of this approach is that it incorporates the total information available with the production technology [16]. In other words, additional information such as production elasticities and elasticities of substitution are taken into account and should be beneficial to estimating the parameter of market power. These advantages encourage this study to follow the NEIO approach.

Much of the literature on industrial organization refers to market power in the beef packing industry. For example, Schroeter (1988) extends Appelbaum's technique and measures the market power of the U.S. beef packing industry. The result reveals small but statistically significant monopoly and monopsony price distortions in slaughter cattle and wholesale beef markets [17]. Later, Azzam (1997) measures the U.S. beef-packing industry using an oligopsony analogue of Williamson's trade-off model [18]. Morrison (2001) estimates the beef packing industry in the U.S., where slight market power is exploitable in the cattle input or beef output markets [19]. Panagiotou and Stavrakoudis (2017) estimate that the degree of market power in the U.S. beef packing industry was $3.74 \%$ by using a stochastic frontier estimator [20]. Ji, Chung, and Lee (2017) estimate the existence of oligopsony power in the U.S. cattle market. They state that the market power is influenced by the cattle cycle and seasonality. The processors tend to increase their margin during the excessive cattle supply period while preserving a lower margin during the short supply period [21]. There are few empirical studies of the Canadian beef packing industry. Rude, Harrison, and Carlberg (2011) develop an econometric model to measure market power in the Canadian beef processor market which suggests little evidence of oligopsony market power [22].

Several studies modify and extend the basic framework. John Schroeter (1988) assumes a homogeneous output and fixed proportions of output, with single material input. Shephard's Lemma demand and generalized Leontief functions of cost are used. He puts forward the revenue model with profit, material input cost, and non-material input cost by calculating the first-order condition to get a firm's conjectural elasticity $\theta$, which is the firm's perceived rate of change of market output (material input) with respect to its own output [17]. Koontz and Garcia (1997) use a non-cooperative game-theoretic model to study the cattle packing industry [23]. Muth and Wohlgenant (1999) use marginal input and output prices to measure market power in the U.S. beef packing industry. They affirm that beef packing has market power under a no-fixed-proportions assumption between live cattle inputs and processed beef output and non-constant returns-to-scale technology [24]. Morrison (2001) develops a model to estimate monopoly power and monopsony power simultaneously [19]. Yamaura and Featherstone (2016) examine the difference between the unrestricted and restricted profit function results under market power, which contributes to the production technology of market power estimation [25].

From the 1970s, the concentration ratio of U.S. cattle slaughter increased rapidly. Therefore, many authors began to estimate processor market power with structural and economic factors including industry concentration, price transmission, cost efficiency, and so on. Basic economic principles indicate that high concentration will lead to market power and inefficiencies. However, the concentration may lead to a lower marginal cost. Thus, the influence of market power is complicated. Azzam and Schroeter (1997) state that the cost savings to neutralize the anti-competitive effects of consolidation in the beefpacking industry are about $50 \%$ of the actual cost savings from economies of scale. The results suggest that the material-input margin combines a market power component and a marginal processing cost component. In spite of the increase in buyer concentration, the beef market has borne a cost. The benefits are large enough to counteract the costs [18]. 
Morrison (2001) estimates the beef packing industry in the U.S., where the apparent evidence is offset by cost efficiencies such as scope economies and utilization [19]. Azzam and Andersson (2008) estimate the Swedish beef processing industry and reveal that the cost-efficiency effect of cooperatives concentration counteracts its market power effect, giving rise to lower beef prices [26]. Wohlgenant (2013) states that prices received by producers or prices paid by consumers have no adverse effect on the concentration in procurement of livestock [27].

Apart from the estimation of market power with concentration, there are some studies relating market power with other industrial factors in the beef packing industry. For instance, Christopher et al. (2013) use an agent-based auction model to discover the changes in beef packers' market power in the U.S. It suggests that market power can be reduced by the noisy signal of buyers or sellers according to the increasing competition between buyers [28]. Surathkal and Chung (2019) estimate the potency of packers' inventory and market power for price adjustments in the U.S. beef industry. Their results suggest that market power has an impact on asymmetric price transmission. When the price decreases, the packers' market power will slow down the price adjustment [29]. Chung, Park, and Lee (2018) find that the processors' market power degree is greater than the retailers' market power degree in the U.S. beef industry [30].

The issue of market power is highly correlated to policy study. There are many articles estimating the market power effects of the Livestock Mandatory Reporting Act (LMRA) in the U.S. beef industry [20,31-33]. These prove that the market power exertion of fed cattle markets was greater in the years after the program was implemented than before.

Much research is related to market power in the beef sector, but few studies focus on the Irish beef sector. Some scholars examine the concerns of Irish consumers for the safety of Irish beef [34], consumer perceptions of the risk associated with beef, and factors influencing consumers' purchase factors [35,36]. Cillero et al. (2018) explore the effect of coupled payments on the technical efficiency of specialist Irish beef farms [37]. Binfield and Jennessy (2001) assess the Irish beef industry structure by projecting the influence of Agenda 2000 on the beef sector [38]. Crosson et al. (2006) develop a mathematical model to investigate Irish beef production systems [39]. Moreover, the research on beef producer organizations indicates that stakeholders have not emphasized the benefits of Interbranch organizations [40]. Fischer and Hartmann (2010) take the Irish beef industry as an instance to estimate options for coordinating agricultural markets [41]. Jim Power (2020) examines the current challenges faced by beef production in Ireland, providing a precise review of the Irish beef production industry [42]. Previous studies on the Irish beef sector focus on the technology and production system aspects. As far as we know, there is no existing paper researching the market power of the Irish beef sector. The lack of research on market power in the Irish beef sector leaves us with no empirical testimony as to whether the asymmetries of power within the beef supply chain described as favouring processors and retailers result in the poor economic viability of beef. Therefore, the main objective of this study is to determine the conduct of beef processors in the market for finished cattle in Ireland to address a gap in the fields of industry organization and the Irish beef processing industry. It will be the first paper to apply an empirical estimation concerning price distortions and power asymmetries in the Irish beef industry and will contribute to policy analysis.

Based on the significance of market power research and the limitation of Irish beef research, this paper will use structural econometrics to examine whether beef slaughterers exercise market power over farmers to gain more profit. The model employed in this study is based on the framework proposed by Zheng and Vukina (2009), which extends Schroeter's and Azzam's industry model to specify the conjectural elasticity of processors [43]. The model is estimated by using data from Central Statics Office (CSO). The results suggest that a statistically significant market power of beef slaughterers does exist.

The article proceeds as follows: Section 1 presents the background and literature review relating to market power estimates for the Irish beef sector. Section 2 provides 
a detailed description and discussion of the model and dataset. Section 3 discusses the empirical estimation of market power from three aspects: an inverse demand function, an inverse supply function, and a cost function. Section 4 sets out the discussion of the results, including export issues and subsidies. Section 5 displays the conclusion.

\section{Materials and Methods}

\subsection{Model}

The Irish beef processing sector consists of a few large beef slaughtering firms and many smaller abattoirs, which is similar to the U.S. meat packing sector. Following Schroeter, Azzam, and other scholars working on market power in the U.S. meat packing sector, it is assumed that the industry uses $\mathrm{N}$ processors producing a homogenous output and utilizing a single homogenous material input. Another assumption regards the fixed proportion production technology. Therefore, the quantity of cattle input and the quantity of beef output can be presented by the same variable $q^{i}$.

In standard theory, a supply curve is a unique functional relationship comprised of price $(P)$ and quantity supplied $(Q)$, in the form $P=M C(Q)$. For a perfectly competitive firm, the supply curve is consistent with the portion of marginal cost above the average cost. Mathematically, the supply relation is the equality of the perceived marginal revenue and the marginal cost, which is given as:

$$
P(Q, z)=\frac{\partial C\left(q_{i}, \boldsymbol{w}\right)}{\partial q_{i}}-\lambda_{i} \frac{\partial P(Q, z)}{\partial Q} q_{i}
$$

The supply relation is transformed as the equilibrium of the marginal revenue and the marginal cost. The firm faces an inverse demand function $P(Q, z)$ where price $(P)$ is a function of industry output $(Q)$. The firm's output $\left(q_{i}\right)$ enters the revenue relation, and the cost function. $z$ is a vector of exogenous demand-shift variables. $\partial C / \partial q_{i}$ is the firm-specific marginal cost, $w$ is a vector of exogenous cost-shift variables, and $\partial P / \partial Q$ is the slope of inverse industry demand. $\lambda_{i}$ is a parameter to be determined. The general interpretation for $\lambda_{i}$ is that it is a measure of the equilibrium wedge between the price and the marginal cost. Applebaum (1982) developed the Production Theoretic approach to exploit the duality between cost and production functions [15]. The key point is to assume the cost functions of the Gorman polar form. The approach provides the fundamental theory for the following model.

The characterization of market power aims to determine whether the procurement price has been lower than the competitive level. Therefore, the hypothesis assumed is that the processor is able to adjust the quantity purchased below competitive levels in order to mark down the price by exploiting the upward-sloping cattle supply function. This can be estimated by a profit-maximizing framework. A processor $i$ 's profit model is developed as:

$$
\pi_{t}^{i}=W_{t} q^{i}-P_{t} q^{i}-C_{t} q^{i}
$$

where $\pi_{t}^{i}$ is the profit for the processor $i ; W_{t}$ is the price of the processor's beef; $P_{t}$ is the price of cattle; $C_{t} q^{i}$ is the production cost of processor $i$.

The first-order condition for profit maximization with respect to cattle quantity is:

$$
\frac{\partial \pi_{t}^{i}}{\partial Q_{t}}=\frac{\partial W_{t}}{\partial Q_{t}} \frac{\partial Q_{t}}{\partial q^{i}{ }_{t}} q^{i}+W_{t}-\frac{\partial P_{t}}{\partial Q_{t}} \frac{\partial Q_{t}}{\partial q^{i} t} q^{i}-P_{t}-\frac{\partial C_{t} q^{i}}{\partial Q_{t}}
$$

The first two terms on the right-hand side are the value of marginal product (VMP). In a competitive industry, the VMP equates to the marginal factor cost (MFC). The term $q^{i}$ shows how firm $i$ 's cattle procurement determines the overall meat processing industry and in turn affects the price of cattle. $\partial W / \partial Q$ is the slope of inverse industry demand, and $\partial P / \partial Q$ is the slope of inverse industry supply. To complete Equation (3), it is necessary to develop econometric models which include an inverse demand function and an inverse supply function to identify the value of the marginal product and the marginal cost. 
The theoretical model used here is developed by Zheng and Vukina (2009), where it is applied to the estimation of market power in the U.S. pork packing industries. In the U.S., authors always estimate the combined pork and beef industry as the meat industry, which suggests that this model for the pork packing industry is also suitable for the beef packing industry. There are other advanced models estimating market power, but there is a limitation on data which is beyond the scope of this paper. For example, most data on the Irish beef industry are industry-level data. So, a firm-level model is not suitable. Some models require labour cost, which is only available for quarterly data. Considering these factors, we decided to adopt the theoretical model proposed by Zheng and Vukina (2009) [43].

The inverse demand function for cattle is given by:

$$
\log W_{t}=\gamma_{0}+\eta \log \left(Q_{t}\right)+\gamma_{1} \log p_{p}+\gamma_{2} \log p_{s}+\gamma_{3} \log p_{p o}+\gamma_{t} t+\gamma_{t s q} t^{2}+e_{d t}
$$

where $p_{p}, p_{s}$, and $p_{p o}$ refer to the price of the main substitutes of beef, including pork, sheep, and poultry, respectively. $Q_{t}=\sum_{i}^{N} q_{t}^{i}$ is the total quantity of cattle that $\mathrm{N}$ processors procure. $\eta$ means the inverse demand elasticity for beef. The summary of data indicates that the data might have a long-term trend. To control for trend effects, the time dummies $t$ and $t^{2}$ are added. Since the unit of price and the price indices are variant, a log function is applied to make them consistent. In addition, following Schroeter, we assume the error following an $\mathrm{AR}(1)$ process where $E\left(e_{d t}\right)=0$.

The inverse supply function for cattle is:

$$
\log P_{t}=\delta_{0}+\varepsilon \log \left(Q_{t}\right)+\delta_{1} \log p_{f}+\delta_{t} t+\delta_{t s q} t^{2}+\delta_{m} D_{m t}+e_{s t}
$$

where $p_{f}$ is the input price. Considering the available data, the input seed price and the input energy price are used to represent the input price, and $\varepsilon$ is the inverse supply elasticity for cattle. Besides the trend dummies, $D_{m t}$ represents the monthly dummies, omitting the month December. As the cattle supply has a particular seasonal feature, it is better to take the seasonal fluctuation into consideration. The set of monthly dummies is to control for seasonal effects. In addition, following Schroeter, we assume the error following an AR(1) process where $E\left(e_{s t}\right)=0$. Importantly, $\frac{\partial W_{t}}{\partial Q_{t}}=\frac{\eta\left(W_{t}\right)}{Q_{t}}$ and $\frac{\partial P_{t}}{\partial Q_{t}}=\frac{\varepsilon\left(P_{t}\right)}{Q_{t}}$ can be calculated from Equations (4) and (5).

The following specifies the cost function with Porter's cost function as:

$$
C_{t}\left(q_{t}^{i}\right)=\theta_{1} q_{t}^{i}+\theta_{2}\left(q_{t}^{i}\right)^{2}+F
$$

This function is the Gorman form, and it is quadratic in quantities which meet the condition for the Production Theoretic approach. F represents the fixed cost. (The generalized Leontief cost function is widely used in other studies which require input prices and input quantity. As this article uses monthly data, the input variables such as labour are not available for monthly data.)

The above equilibrium is based on firm-level data. As our data are industry-level, the equation cannot be specified. Equation (3) needs to be transformed to an industry version. To do so, we assume that there are $\mathrm{N}$ slaughterers with market power. Then, for the industry-level quantity, $q_{t}^{i}$ equals to $\frac{Q_{t}}{N} \cdot \phi^{i}{ }_{t}$ is a measure of the market power processor $i$ enjoys. The assumption is that $\phi^{i}{ }_{t}=\phi_{t}$. Then, Equation (3) is given as:

$$
W_{t}-P_{t}+\frac{\eta W_{t} \phi_{t}}{N}-\frac{\varepsilon P_{t} \phi_{t}}{N}-\theta_{1}-\theta_{2} \frac{Q_{t}}{N}=0
$$

If $\phi_{t}>0$, it suggests that the processor has market power over farmers. If $\phi_{t}=0$, it suggests that the beef market is perfectly competitive. And if $\phi_{t}=1$, there is a monopoly in the beef market. The term $\left(W_{t}-P_{t}\right)$ is the gap between the slaughter price and the farm price. If the market is perfectly competitive, the slaughterers cannot lower the price 
below the competitive price level. So, the difference on the slaughter price and the farm price is only affected by the production $\operatorname{cost}\left(\theta_{1}+\theta_{2} \frac{Q_{t}}{N}\right)$. In contrast, if the market is an oligopoly, then the slaughterers exercise power to control the price. The gap between the slaughter price and the farm price is also influenced by the elasticity of demand $1 / \eta$ and the elasticity of supply $1 / \varepsilon$. The term $\left(\frac{\eta W_{t} \phi_{t}}{N}\right)$ is a measure of the slaughterers' benefits in the downstream market due to their market power in the upstream.

To test whether market power exists, model $\phi_{t}$ is represented as:

$$
\phi_{t}=\phi_{0}+\theta_{t} t+\theta_{t s q} t^{2}
$$

This function specifies the slaughter conjecture in period $t$.

\subsection{Data}

The data used for this paper are from the Central Statics Office (CSO), which is Ireland's national statistical office. It collects, analyses, and makes available statistics about Ireland's people, society, and economy. The breakout in Ireland of Bovine Spongiform Encephalopathy (BSE), commonly known as Mad Cow Disease, caused some missing data in 2004. To avoid the influence of BSE, data for the period from January 2005 to October 2019 are used in this study. Some data are only available monthly, which, considering a time period as long as 15 years, is reasonable for estimation. The total number of observations is 178.

Within the Irish beef system and classification, a suckler cow herd, which is a healthier grass-fed herd, contributes a lot to the large and productive beef sector [2]. The suckler herb establishes a strong reputation for high-quality prime beef and live cattle. Burke (2016) points to the carcasses produced from suckler herds resulting in a superior carcass classification with regard to conformation [44]. The environmentally sustainable grassbased system of production with relatively low cash costs is competitive vis-à-vis other EU producers. According to the Irish government, there are 1.1 million beef suckler cows in under 80,000 farms. These cows calve once a year, usually in Spring, and calves are weaned nine months later. The Irish beef system includes suckling (to weanlings); suckling (to stores); suckling (to finished); finishing (store to finished); calves reared on dairy farms; and mixed production systems [44]. Based on the EU Beef Carcass Classification Scheme, which classifies beef following conformation (the shape and development of the carcass), fat, and sex category, the cattle include young bull, bull, cow, and heifer (DAFM).

Bullock price is chosen to represent the cattle price. Bullocks, also known as steers, are castrated male bovines raised for meat. A bull is a mature male bovine that is at least 2 years old and used for breeding purposes. Heifers are young female cattle that have not yet borne calves. Once a heifer has a calf, it becomes a cow, which refers to a mature female bovine that has had at least one calf. Calves are baby male and female cattle. This classification specifies cattle according to different stages and uses. Bullocks are the main type of cattle for meat. And based on kill quantity data, they are the main type of cattle sent to processors for beef. The most traded type of cattle between farms and processors is bullock. Hence, taking bullocks' price as cattle price is reasonable. The data are collected per $100 \mathrm{~kg}$ in euro. The data shows that the cattle price fluctuated a lot over the 15 years, with an upward trend. The highest price appears in 2012, and the lowest price was in 2009, which may suggest a fierce fluctuation during 2009 and 2012. According to the annual DAFM report of 2009, beef output declined in 2009 due to a composition of inferior cattle availability, compressing global commodity prices, and the economic downturn. The strong cattle price in 2012 could have been caused by a fall in finished cattle supplies coupled with a strong demand in the main export market $[8,45]$. As cattle production follows a dynamic cycle which can last for two years, the cattle stock and variable cattle demand have a delayed influence on cattle price. Figure 1 also presents the seasonal feature of price. In general, spring is the peak time for price, and in autumn it reaches an all-time low, which is consistent with the yearling period. 


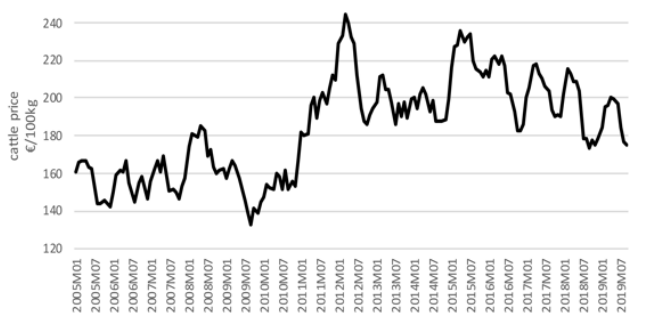

(a)

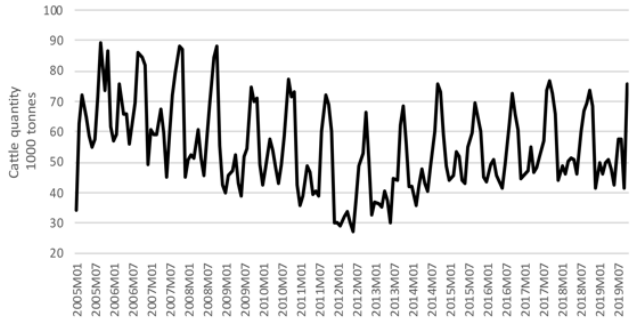

(b)

Figure 1. Cattle price and cattle quantity trend from January 2005 to October 2019. (a) Cattle price trend from January 2005 to October 2019; (b) Cattle quantity trend from January 2005 to October 2019.

The weight of slaughtered bullocks is used to measure the quantity of cattle. Instead of the number of processors per head, weight is consistent with the unit of cattle price, in euro, per $100 \mathrm{~kg}$. Cattle quantity shows a particular fluctuation trend. It has similar fluctuations in different years. The quantity usually reaches the highest number in September or October, and there is a wide gap between the maximum and the minimum quantity, which means that the fluctuation of quantity is fierce. There is no obvious decreasing or increasing trend over the 15 years, which may imply that the change in cattle demand is small. The graph implies that the total quantity is lowest in 2012, which is consistent with the year of the highest price. Jim Power (2020) states that the weak demand trends for beef are due to a combination of fierce export competition, decreasing world prices due to the completed rebuilding of the US herd, and the reaped supplies expected from Brazil and Argentina [42].

The price of slaughter beef is set to be the deadweight price of steer per $100 \mathrm{~kg}$, in euro. The CSO provides the deadweight price for bulls, steers, cows, and heifers. As stated before, steers are castrated male bovines raised for meat. So, the deadweight price of a steer is applied to estimate the slaughter price of beef. The slaughter price has a trend and fluctuation similar to those of the cattle price, and it is always higher than the cattle price, which implies that the slaughter price must be higher than the farm price.

In addition to cattle price and quantity data, substitute prices and cost prices data are necessary. The approach accounts for the total information available on the production technology by using additional information to estimate the parameter of market power. The cost price will be used to build the cost function, and the substitute price is necessary for the demand function. Beef is the biggest category within the meat sector, pig production ranks are the second, and Irish sheep production has also experienced consecutive growth during these years. Ireland is also the highest consumer of poultry meat in the EU. Therefore, output price indices of pork, sheep, and poultry are used as the price of the substitutes. The output price indices are based using a 2015 setting as 100, which is the index of the producer prices of agricultural products. Provided by the CSO, it is based on the sales of agricultural products and includes the value of production sold to dealers. Prices are based on the market price concept. Moreover, the input price indices of seed, energy, and electricity will be indicators for the cost price. The input prices used are those actually paid by farmers, excluding VAT. According to the CSO, seeds are seasonal products, so the monthly prices remain unchanged until the product can be priced again. Table 1 presents the summary of statistics. 
Table 1. Summary statistics.

\begin{tabular}{|c|c|c|c|c|c|c|}
\hline Variable & Definition & Unit & Mean & Std. & Min & Max \\
\hline$P_{t}$ & Cattle price & Per $100 \mathrm{~kg}$ in $€$ & 184.20 & 26.32 & 132.78 & 244.41 \\
\hline$Q_{t}$ & Cattle quantity & 1000 tonnes & 19.37 & 4.98 & 9.90 & 31.90 \\
\hline$W_{t}$ & Processors price & Per $100 \mathrm{~kg}$ in $€$ & 333.73 & 49.50 & 229.82 & 428.70 \\
\hline$p_{p}$ & Pork price & $\begin{array}{c}\text { Price indices } \\
(\text { Base } 2015=100)\end{array}$ & 100.36 & 9.92 & 79.39 & 123.98 \\
\hline$p_{s}$ & Sheep meat price & $\begin{array}{c}\text { Price indices } \\
(\text { Base } 2015=100)\end{array}$ & 90.37 & 13.95 & 64.00 & 128.35 \\
\hline$p_{p o}$ & Poultry price & $\begin{array}{c}\text { Price indices } \\
(\text { Base } 2015=100)\end{array}$ & 93.45 & 8.84 & 73.53 & 104.20 \\
\hline$p_{f}$ & Seed price & $\begin{array}{c}\text { Price indices } \\
(\text { Base } 2015=100)\end{array}$ & 95.86 & 8.77 & 83.04 & 113.18 \\
\hline$p_{e}$ & Energy price & $\begin{array}{c}\text { Price indices } \\
(\text { Base } 2015=100)\end{array}$ & 97.69 & 13.31 & 68.89 & 121.21 \\
\hline
\end{tabular}

\section{Results}

In order to estimate the above equations and verify the market power, a system of simultaneous equations is necessary. The generalized method of moments (GMM) is used in this study. GMM is a statistical method that combines observed economic data with the information in moment conditions to produce estimates of the unknown parameters of this economic model. Those parameters could explain the economic performance to a certain degree. The idea behind GMM estimation is that once it is impossible to solve the system of equations provided by the sample moment conditions, an estimate of $\theta$ that brings the sample moments as close to zero as possible can be examined [46]. GMM estimators are known to be more efficient in the condition that the random error term is heteroscedasticity or autocorrelation. The full information method is not used, as any specification error in any equation of the model would be magnified, and the GMM method can estimate equations separately to measure a linear function of the parameters.

\subsection{Demand for Cattle}

The inverse demand function for cattle of Equation (4) is the system GMM estimation which was undertaken in the model by Zheng and Vukina (2009) [43]. Additionally, there are two issues to be discussed to specify the instrumental variables of the GMM model. Firstly, as the equilibrium quantity is simultaneously determined with the price, the output quantity $\log \left(Q_{t}\right)$ might be endogenous. Therefore, instrumental variables are applied for the output quantity. Considering this is a demand function, supply shifters are feasible alternatives. In Ireland, yearling buys usually happen in March. Bullocks are usually killed between December and February. Farmers' decisions on yearling quantity are relevant to the previous price. In light of this, four instruments are applied: the price for seed one month ago and two months ago; the price for cattle one month ago and two months ago. The price for seed is relevant to the cost, and the price for cattle is relevant to the profit. Both the cost and the profit are the two main considerations for investment decisions. The single-equation two-step optimal GMM estimation is used to measure the inverse demand function. Another issue is the error term, which may be autocorrelated and heteroscedastic. While the GMM is still asymptotic efficient, asymptotic normality, and consistent, the Heteroskedasticity-Autocorrelation Standard Error for measurement, which is also known as the Newey-West Standard Error, is adopted.

Table 2 presents the estimation results for the inverse demand for cattle. The sample size is reduced to 176 as the lagged instrumental variables. Before analysing the results, the model needs to be specified. Firstly, the $\mathrm{Wu}-\mathrm{Hausman}$ test is applied for the endogeneity of the variables. The statistic is 28.95 , which is significant at the $1 \%$ level to reject the hypothesis that variables are exogenous. This implies that the instrumental variables are necessary. Secondly, the Hansen's J statistic is 1.61 in the three degrees of freedom, which is insignificant at a $10 \%$ level. Therefore, we cannot reject the hypothesis that all instrumental 
variables are exogenous, and the restriction is overidentified. Thirdly, the Cragg-Donald Wald F statistic is 7.50, which is significant at the $1 \%$ level. Thus, we reject the hypothesis that there are weak instruments. The above tests prove the specification and efficiency of the instrumental variables, and the model is specified.

Table 2. Estimation results for the inverse demand for beef.

\begin{tabular}{ccc}
\hline Variable & Estimate & t-stat \\
\hline$\gamma_{0}$ & 2.218 & 2.77 \\
$\eta$ & -0.162 & -5.80 \\
$\gamma_{1}$ & 0.387 & 4.86 \\
$\gamma_{2}$ & 0.020 & 0.31 \\
$\gamma_{3}$ & 0.434 & 2.64 \\
$\gamma_{t}$ & -0.000 & 0.46 \\
$\gamma_{t s q}$ & 0.000 & 0.66 \\
Wu-Hausman & 28.95 & - \\
Hansen's $J$ & 1.61 & - \\
Cragg-Donald Wald & 7.50 & - \\
Number of Obs. & 176 & - \\
\hline
\end{tabular}

Table 2 also presents the examined coefficients of the inverse demand function. The inverse demand elasticity $\eta$ is negative and significant at the $1 \%$ level. The statistic is -0.162 , so the demand elasticity is about -6.173 . The change in quantity demanded over the change in price is negative. It suggests the own-price elasticity for beef is negative, which reveals that the demand for cattle quantity increases while the beef price decreases. The result is consistent with previous studies. Schroeter (1988) estimated the demand elasticity of the U.S. beef packing industry from the period from 1951 to 1983 as -0.527 [17], and Quagrainie, Unterschultz, Veeman, and Jeffrey (2003) estimated the own-price elasticity of demand for cattle from the period 1960 to 1997 in the Canadian beef packing industry as -3.863 [47]. The demand elasticity is high. There is no existing research or articles on the elasticity of demand in the Irish cattle market to verify this result, but previous research on the U.S. and Canadian beef packing markets could offer some explanation. John M. Marsh (2003) estimated the effects of U.S. beef demand on beef production and prices. The result shows that a reduction in beef demand could lead to a decrease in real slaughter cattle prices and production by $32.1 \%$ and $11.2 \%$, respectively. Real feeder cattle prices and production could decrease by $8.0 \%$ and $22.6 \%$, respectively [48]. Considering that Irish beef industry is export-oriented, the demand elasticity could be highly relevant to the export price, rather than the domestic price, and the U.K. accounts for more than $50 \%$ of the export market. Thus, the National and Community Bullocks Average Market Price of the U.K. from the European Commission is applied, as the country's deadweight price to the demand function. A new demand elasticity, which is -0.17 and significant at a $1 \%$ level, is testified. The result suggests that U.K. prices have a significant effect on the demand elasticity of Irish beef, but the influence is limited.

The cross-price elasticities for pork, sheep meat, and poultry are all positive, which means that given a rise in their price, the demand for beef will increase. This is consistent with our expectation of substitutes. In theory, the cross-price elasticity is positive when goods are substitutes. However, the statistic of sheep meat price is not significant at a $10 \%$ level. Therefore, we can reject the hypothesis that a change in sheep meat price influences the demand for beef. This suggests that poultry and pork are higher-level substitutes for beef demand compared to sheep meat. The statistic for time trend is not significant at the $10 \%$ level, and therefore we can reject the hypothesis that changes in cattle price show a trend.

\subsection{Supply for Cattle}

To estimate the inverse supply function for cattle, there are two issues to be discussed. Firstly, the variable $\log p_{f}$ needs to be decided. $\log p_{f}$ is the input price, which could 
include feed price and fuel price. Thus, it is set as the seed price and energy price. Similar to the demand function estimation, the output quantity $\log \left(Q_{t}\right)$ needs to be specified. Considering the endogeneity problem, instrumental variables for output quantity are used: the beef price lagged one month. Beef price is the demand shifter for the supply function. The single-equation two-step optimal GMM estimation is applied to measure the inverse supply function. The model includes a set of monthly dummies $D_{m t}$ (the month November is omitted) to control for seasonal effects.

Table 3 presents the estimation results. The sample size is 177, which was reduced by one as the lagged instrumental variable. The statistic of the $\mathrm{Wu}-\mathrm{Hausman}$ test for endogeneity is 220.146, which is significant at the $1 \%$ level, rejecting the hypothesis of exogenous variables. The Cragg-Donald Wald F statistic is 4.650, which is significant at the $5 \%$ level, sufficient to reject the hypothesis of weak instruments. Apart from the beef price lagged by one month, the beef price lagged by two months and the feed price are also applied. These are not significant at the 10\% level, suggesting the weak instrument. Hence, only the beef price lagged by one month is taken as the instrumental variable. These test results meet the requirement for model specification and efficiency, and prove the specification of the instrumental variable.

Table 3. Estimation results for the inverse supply for beef.

\begin{tabular}{ccc}
\hline Variable & Estimate & t-stat \\
\hline$\delta_{0}$ & -19.008 & -2.82 \\
$\varepsilon$ & 0.187 & 3.12 \\
$\delta_{1}$ & & \\
lnseed & 3.298 & 3.77 \\
lnenergy & 0.890 & 2.14 \\
$\delta_{t}$ & 0.018 & 2.95 \\
$\delta_{\text {tsq }}$ & -0.000 & -2.78 \\
$\theta_{m}$ & & \\
January & 1.499 & 2.27 \\
February & 1.508 & 2.34 \\
March & 1.165 & 2.36 \\
April & 1.170 & 2.35 \\
May & 1.442 & 2.34 \\
June & 1.664 & 2.29 \\
July & 1.007 & 2.19 \\
August & 0.343 & 1.71 \\
September & -0.404 & -1.81 \\
October & -0.476 & -1.89 \\
December & 1.528 & 2.20 \\
Wu-Hausman & 220.146 & - \\
Cragg-Donald Wald & 4.650 & - \\
Number of Obs. & 177 & - \\
\hline
\end{tabular}

Turning to the coefficient estimation, the inverse elasticity of supply $\varepsilon$ is positive and significant at the $5 \%$ level. The statistic is 0.187 , while the elasticity of supply is 5.351 . This indicates that an increase in the quantity supplied will lead to an increase in cattle price. Schroeter (1988) estimated the supply elasticity of the U.S. beef packing industry as 1.689 from 1951 to 1983 [17]. This concurs with previous studies on supply elasticity. The seasonal variability of Irish beef supply could lead to a relatively high supply elasticity in some circumstances, with beef production profoundly affected by weather conditions, which can reinforce elasticity.

The parameter of seed price is significant at the $5 \%$ level and is positive, which suggests that higher seed prices will cause higher cattle prices. The parameter of energy price is significant at the $10 \%$ level, which is also positive. Crosson, $\mathrm{O}^{\prime}$ Kiely, $\mathrm{O}^{\prime} \mathrm{Mara}$, and Wallace (2006) built a mathematical model of the Irish beef production system, which reveals that feed costs are the primary costs in the Irish beef production system [39]. The 
key concerns for beef farmers are beef prices and concentrate prices (feed prices), and the alteration in beef price can culminate in substantial adjustments to optimal beef production systems. The Irish beef sector is a grass-fed herd, according to Paul Crosson (2016), where $70 \%$ of the variable costs for beef farmers are feed costs along with fixed costs incurred from feeding machinery and storage facilities [49]. Therefore, it is reasonable to assume that higher seed prices cause higher cattle prices.

The parameter of time trend is significant at the $5 \%$ level. The hypothesis that supply has a long-term trend cannot be rejected. The month dummies have significant effects, which are significant at the $10 \%$ level. The results seem to indicate that cattle supply has a certain seasonal fluctuation. Crespi, Xia, and Jones (2010) estimate that the production cycle is critically related to a posited cycle of bargaining positions among cattle producers and beef processors [50].

\subsection{Cost Function and Market Power Estimation}

The final step is to estimate Equation (7). Insert Equations (4) and (5) to rearrange the equation as:

$$
W_{t}-P_{t}=-\frac{\eta W_{t} \phi_{t}}{N}+\frac{\varepsilon P_{t} \phi_{t}}{N}+\theta_{1}+\theta_{2} \frac{Q_{t}}{N}=\theta_{1}+\theta_{2} \frac{Q_{t}}{N}+\left(\frac{\varepsilon P_{t}}{N}-\frac{\eta W_{t}}{N}\right) \phi_{t}
$$

Then insert Equation (8) to take market power into calculation as:

$$
\begin{gathered}
W_{t}-P_{t}=\theta_{1}+\theta_{2} \frac{Q_{t}}{N}+\left(\frac{\varepsilon P_{t}}{N}-\frac{\eta W_{t}}{N}\right)\left(\phi_{0}+\theta_{t} t+\theta_{t s q} t^{2}\right) \\
=\theta_{1}+\theta_{2} \frac{Q_{t}}{N}+\phi_{0}\left(\frac{\varepsilon P_{t}}{N}-\frac{\eta W_{t}}{N}\right)+\theta_{t} t\left(\frac{\varepsilon P_{t}}{N}-\frac{\eta W_{t}}{N}\right)+\theta_{t s q} t^{2}\left(\frac{\varepsilon P_{t}}{N}-\frac{\eta W_{t}}{N}\right)
\end{gathered}
$$

Equation (10) is the final version to be estimated and calculated. While it is a non-linear equation, $\varepsilon$ and $\eta$ are derived from the inverse supply equation estimation and inverse demand equation estimation, which turns Equation (10) into a linear model and makes the final estimation easier. We still use the single equation two-step optimal GMM as an estimator. As $\varepsilon$ and $\eta$ are estimated from the first stage regressions, in the second stage, the variance of the first stage parameter needs to be considered. Hence, we simulate a set of $\varepsilon$ and $\eta$ from their estimated distributions in the first regressions and randomly generate 178 sets of data from a normal distribution with the same mean and standard deviation as the statistic of $\varepsilon$ and $\eta$. For instance, the estimated number of $\eta$ is -0.162 , and the standard deviation is 0.003 . Hence, this set of 178 data is normally distributed, with -0.162 mean and 0.003 standard deviation.

The last issue is to decide the statistic of $\mathrm{N}$ in the estimation. $\mathrm{N}$ is the number of slaughter facilities that can confer market power to farmers. According to the European Commission, in 2015, the combined ABP/Slaney entity was estimated to own 20-30\% of the market. Dawn and Kepak had 1-20\% each, and Liffey, Kildare, and Dunbia accounted for $5-10 \%$ each. Others had about $20-30 \%$. Based on this industry fact, $\mathrm{N}$ was set as 7.

Table 4 shows the result. The constant $\theta_{1}$ and the slope $\frac{\theta_{2}}{N}$ are the marginal cost function. $\theta_{1}$ is positive and significant, and $\theta_{2}$ is positive and insignificant. The average marginal cost is calculated by $4.300+(0.002 \times 19.372 / 7)$. The statistic is about 4.200 , while $\phi_{t}$ is the indicator for market power, equalling $\phi_{0}+\theta_{t} t+\theta_{t s q} t^{2}$. By calculation, the average $\phi_{t}$ is 0.086 . The coefficients of the time dummies are significant. Hence, the time dummy has a significant effect on market power.

Turning to the parameter estimates, the results are shown in Table 5. The average marginal cost is 4.200 euro per $100 \mathrm{~kg}$, implying that the price spread is used to cover the production cost. The average $\frac{\eta W_{t}}{N} \phi_{t}$ is the meat processor's markup in the downstream market, which is about 0.674 euro, and the price markdown to the cattle market is $\frac{\varepsilon P_{t}}{N} \phi_{t}$, which is about 0.010 euro. Schroeter suggests that markdown values of $1 \%$ to $3 \%$ are modest. Stiegert, Azzam, and Brorsen (1993) estimated the markdown pricing in the U.S. beef packing industry and found that the average markdown was $1.31 \%$, which represents 
$\$ 1.54$ of retail beef sold per 100 pounds [51]. The price markdown in the Irish cattle market is not as strong as in that study, which suggests that the main benefit of meat processors' market power is price distortion in the beef market rather than price distortion on farmers. However, the markdown is above 0 , which suggests that the farmer-received price is below the break-even point. In other words, meat processors do utilize market power to lower farmers' price and obtain profits.

Table 4. Cost function and Market power estimation $(N=7)$.

\begin{tabular}{ccc}
\hline Variable & Estimate & t-Stat \\
\hline$\theta_{1}$ & 4.300 & 50.10 \\
$\theta_{2}$ & 0.002 & 0.51 \\
$\phi_{0}$ & 0.057 & 3.71 \\
$\theta_{t}$ & 0.001 & 4.45 \\
$\theta_{t s q}$ & -0.000 & -3.30 \\
Number of Obs. & 177 & - \\
\hline
\end{tabular}

Table 5. Quantifying the magnitude of market power.

\begin{tabular}{cc}
\hline Variable & Estimate \\
\hline Average $\theta_{1}+\theta_{2} \frac{Q_{t}}{N}$ & 4.200 \\
Average $\frac{\varepsilon P_{t}}{N} \phi_{t}$ & 0.010 \\
Average $\frac{\eta W_{t}}{N} \phi_{t}$ & -0.674 \\
Average $\phi_{t}$ & 0.086 \\
\hline
\end{tabular}

The parameter of market power is 0.086 in the interval from 0 to 1 , which meets the assumption, statistically affirms market power, and shows the degree of market power. It can be inferred that beef slaughters exercise market power over famers. Table 6 presents previous studies of the degree of market power for the beef processing industry. The studies before 2000 on the U.S. beef market suggest that the market power degree was between 0 and 0.2. After 2000, the degree of market power increased. In the Canadian beef industry, Love (2005) reports the market power parameter of -0.023 for fed cattle and 0.585 for cull cattle [52]. Rude, Harrison, and Carlberg (2011) find that the market power parameter is 0.31, abstracting from exports [22]. Panagiotou and Stavrakoudis (2017) report the degree of market power as $3.47 \%$, and find the average degree of market power as $5.268 \%$ for the period 1970 to 2001 [20]. This changed to 3.829\% after LMRA [31]. Compared to previous studies, the result is reasonable, while the degree of market power of Irish meat slaughterers is 0.086 , which is higher than most studies indicate. Therefore, we deduce that the market power of Irish slaughterers is in between the other two countries.

Table 6. Overview of empirical studies of the degree of market power for the beef processing industry.

\begin{tabular}{ccc}
\hline Author(s) (Year) & Country & Market Power \\
\hline Schroeter (1988) [17] & U.S. & 0.042 \\
Azzam, Azzeddine M., and Pagoulatos (1990) [53] & U.S. & 0.178 \\
Park and Azzam (1992) [54] & U.S. & 0.032 \\
Muth and Wohlgenant (1999) [24] & U.S. & 0.000 \\
Morrison (2001) [19] & U.S. & 0.0004 \\
Love (2005) [52] & Canada & -0.023 (Fed cattle) \\
Church, Jeffrey, and Gordon (2007) [55] & Canada & 0.585 (Cull cattle) \\
Rude, Harrison, and Carlberg (2011) [22] & Canada & 0.254 \\
Panagiotou and Stavrakoudis (2017) [20] & Canada & 0.31 \\
Panagiotou (2019) [31] & Canada & 0.053 (1970-2001) \\
& & 0.038 (After 2001)
\end{tabular}




\section{Discussion}

\subsection{The Influence of Export on Market Power}

As the largest beef exporter in the EU and the sixth-largest beef exporter globally, Ireland exports over $91 \%$ of its beef production, amounting to about $€ 2.5$ billion. Therefore, beef exports need to be considered when estimating the market power of the beef processing industry. According to Jim Power (2020), around 85\% to $90 \%$ of the Irish producing cattle are slaughtered in Ireland, which implies that the rest are exported as live cattle [42]. We followed Rude, Harrison, and Carlberg (2011) including cattle exports into the conjectural elasticity [22]. This model was designed to estimate the market power of the Canadian beef packing industry, as the Canadian beef industry is also a large export market.

It is assumed that domestic market power is a function of the ratio of live cattle exports to the total sales volume. The conjectural elasticity can be determined as:

$$
\phi=\phi_{1}+\phi_{2}\left(\frac{\text { export volume }}{\text { sales volume }}\right)
$$

Then, transfer Equation (8) is determined as:

$$
\phi=\phi_{0}+\theta_{t} t+\theta_{t s q} t^{2}+\phi_{2}\left(\frac{\text { export volume }}{\text { sales volume }}\right)
$$

The traditional regressors could be the concentration ratio, transportation, and so on. This conjectural elasticity regressor includes exports as a ratio of domestic sales and was the method employed to suggest the cyclical nature of the cattle industry.

Exports of cattle data represent the export volume, and the total numbers of cattle farm animals in December are used for the sales volume data. The unit for these data is a thousand heads. There are no monthly data for live cattle production, only annual cattle production data are available. Therefore, the ratio for $\left(\frac{\text { export volume }}{\text { sales volume }}\right)$ is annual data. The cost function is specified for monthly data, so other variables are still monthly data. Table 7 represents the results of coefficient estimation. The degree of market power is estimated as 0.091. Compared with the statistic 0.086, estimated without export issues, the degree of market power increased. The intercept term $\phi_{1}=\phi_{0}+\theta_{t} t+\theta_{t s q} t^{2}$ is the conjectural elasticity abstracting from the effects of exports, which amount to 0.087 . Term $\phi_{1}$, which is positive, indicates how the ability to export live cattle increases the ability of packers to exert market power. This result contradicts James Rude et. al.'s study, which suggests the ability to export live cattle marks down the exertion ability of packers' oligopsony power, but the statistic is insignificant at $10 \%$. Although Ireland is a large beef exporter, for Irish farmers the export volume of live cattle accounts for a small proportion of the total sales volume. Therefore, this export has no significant effect on market power.

Table 7. Cost function and market power estimation $(\mathrm{N}=7)$ including export ratio.

\begin{tabular}{ccc}
\hline Variable & Estimate & t-Stat \\
\hline$\theta_{1}$ & 4.247 & 28.78 \\
$\theta_{2}$ & 0.005 & 0.94 \\
$\phi_{0}$ & 0.061 & 3.02 \\
$\theta_{t}$ & 0.000 & 3.07 \\
$\theta_{t s q}$ & -0.000 & -2.47 \\
$\phi_{2}$ & 0.146 & 0.72 \\
Number of Obs. & - \\
Average $\theta_{1}+\theta_{2} \frac{Q_{t}}{N}$ & 177 & - \\
Average $\frac{\varepsilon P_{t}}{N} \phi$ & 4.260 & - \\
Average $\frac{\eta W_{t}}{N} \phi$ & 0.011 & - \\
Average & -0.717 & - \\
Average $\phi_{1}$ & 0.091 & - \\
\hline
\end{tabular}




\subsection{The Influence of Subsidy on Market Power}

As mentioned above in the Introduction, Irish cattle farmers are hugely supported by the Basic Payment Scheme and other CAP payments for their income and farm business. The EU Basic Payment scheme commits almost $€ 1.2$ billion to Irish farmers annually. In 2019, the average subsidy payments were up to $158 \%$ of income for cattle farms. Therefore, the huge subsidy payments could affect the measurement of market power. In order to estimate the impact of subsidies on market power, the model developed by Chen and $\mathrm{Yu}$ (2019) is employed, which is empirically designed to measure the effects of subsidies on market power in the Chinese milk market. The Chinese milk market is highly concentrated, with only a few big companies. That is also the case in the Irish beef processing industry [56].

Firstly, the profit function (2) is derived as:

$$
\pi_{t}^{i}=W_{t} q^{i}-P_{t} q^{i}-C_{t} q^{i}+S_{t}
$$

where $S_{t}$ is the subsidies to the farms' output. A model of the Lerner index is obtained as:

$$
\frac{W_{t}-M C_{t}}{W_{t}}=-\frac{Q_{t}}{W_{t}}\left(\frac{\partial W_{t}}{\partial q^{i}} \frac{\partial q^{i}}{\partial Q_{t}}\right)-\frac{P_{t}}{W_{t}} \frac{\partial P_{t} q^{i}}{\partial Q_{t}}-\frac{M S}{W_{t}}
$$

$\Phi=\frac{W_{t}-M C_{t}}{W_{t}}$ is the Lerner index. Then, following Chen and Yu (2019) [56], the empirical model of Equation (11) could be derived as:

$$
\Phi=\alpha_{0}+\alpha_{1} S_{t}+\alpha_{t} t+\sum \alpha_{c} X_{t}+U_{t}
$$

$X_{t}$ is a vector of covariates including variables that could cause market power. Industries usually have a limited number of large firms on account of entry barriers [56]. Four-firm concentration ratio is a reasonable proxy to represent the number of large firms in the industry. In 2015, the average market shares for the purchase of live cattle for slaughter were $62.5 \%$ for the top four beef processors. In 2019, the beef member list on Bord Bia suggests that there were total 66 beef plants. The top four companies owned 27 plants, which implies that their market share was $41 \%$. In May 2002, the 10 principal processors formed Beef Industry Development (BIDS). The BIDS arrangements have restrictions on competition, since they aim to avoid the possible use of plants by new partners entering the market to compete with the participants. These arrangements restrict the entry into the Irish beef processing market to a considerable extent. Therefore, the proxy of entry barrier is not applied in this model, while the average market share is applied. $U_{t}$ is the error term. $S_{t}$ is the subsidies amount at period $t$.

The subsidy data are collected from the CSO. The subsidies for cattle are annual, and the unit is million euro. Table 8 presents the estimation result. The sign of $\alpha_{1}$ informs the interaction between the subsidies and the Lerner index. As $\alpha_{1}$ is negative, it can be inferred that subsidies will lead to a more competitive market. This is consistent with the hypothesis that subsidies eventually reduce market power downstream. However, the statistic is not significant in this estimation. The sign of $\alpha_{c}$ is positive and significant, which suggests that the concentration has a significant impact on the exercise of market power. Previous studies suggest that a high concentration will lead to market power $[18,19]$.

Table 8. Subsidies and Lerner index estimation.

\begin{tabular}{ccc}
\hline Variable & Estimate & t-Stat \\
\hline$\alpha_{0}$ & -0.079 & -0.94 \\
$\alpha_{1}$ & -0.000 & -1.07 \\
$\alpha_{t}$ & 0.001 & 12.80 \\
$\alpha_{c}$ & 0.010 & 6.92 \\
\hline
\end{tabular}




\section{Conclusions}

This paper estimates the market power among farmers and meat processors using a conjectural variation model. In this model, the elasticity of demand and the elasticity of supply are tested to get the meat processors' conjecture of the cattle market by using CSO data. The results show a statistically significant market power. This paper confirms that beef processors can exercise market power over farmers to lower prices below the marginal cost. This estimation is consistent with previous studies on the U.S. and Canadian beef packing markets. Compared with the U.S. beef packing industry, the degree of market power in Irish beef packing is higher. When compared with the Canadian beef packing industry, the degree of market power in the Irish market is not as strong. Apart from market power, the elasticities of demand and supply are higher than in other markets. This indicates that both demand and supply could have a profound impact on beef price and production. Moreover, this paper includes export volumes in conjectural elasticity. The result is not significant, which may suggest that live cattle exports have little impact on market power. In the last section, the influence of subsidies is estimated, showing that subsidies eventually reduce downstream market power.

This study could contribute to the existing literature on the Irish beef industry. It is the first paper to estimate the market power in the Irish beef sector. While there is an ongoing debate on the asymmetrical power between farmers and meat processors, it lacks empirical evidence. The empirical results provide statistical evidence that beef processors exercise market power over cattle farmers. However, the estimation presents a low markdown, suggesting that price distortion is not the main benefit to meat processors in the beef market, while the market power that meat processors can exercise is limited.

This paper has some limitations and remains to be improved by future studies. Firstly, this paper uses industry-level monthly data, which are limited. Market power is applied to estimate price distortion and power asymmetry within the industry. Firm-level data might be more efficient. For instance, the deadweight price is used as the beef price. If the processing firms data could be used, the estimation might be more precise. Furthermore, the data are monthly data, while the estimated sample could be extended. Moreover, this paper uses a conjectural variation model which is widely applied. Some authors estimate the dynamic conduct parameter instead of the average values. If firm-level data were available, the market power estimation in the Irish beef sector would be more comprehensive. Secondly, both exports and subsidies are briefly discussed. With the development of agricultural markets, especially in terms of policy design, the market power estimation model could be extended to discuss exports and subsidies issues from both theoretical and empirical perspectives.

Author Contributions: Conceptualization, R.F. and C.L.; methodology, R.F. and C.L.; software, R.F.; validation, R.F.; formal analysis, R.F.; data curation, R.F.; writing—original draft preparation, R.F.; writing-review and editing, R.F., C.L. and L.W.; visualization, R.F.; supervision, C.L. and L.W. All authors have read and agreed to the published version of the manuscript.

Funding: This research received no external funding.

Institutional Review Board Statement: Not applicable.

Informed Consent Statement: Not applicable.

Data Availability Statement: The data used for this paper are from the Central Statics Office (CSO) which is Ireland's national statistical office. It collects, analyses, and makes available statistics about Ireland's people, society, and economy. The link to the public datasets is: https:/ /www.cso.ie/en/ (accessed on 5 June 2021).

Acknowledgments: The authors thank Carlo Russo (University of Cassino and Lazio Meridionale) for the valuable comments and feedback which helped to improve the manuscript.

Conflicts of Interest: The authors declare no conflict of interest. 


\section{References}

1. Bord Bia (the Irish Food Board). Export Performance \& Prospects: Irish Food, Drink E Horticulure 2019-2020; Department of Agriculture, Food and the Marine: Dublin, Ireland, 2020.

2. Hennessy, T.; Doran, J.; Bogue, J.; Repar, L. The Economic and Societal Importance of the Irish Suckler Beef Sector; Report prepared for the Irish Farmers' Association: Cork, Ireland, 2018; p. 83.

3. Heery, D.; O’Donoghue, C.; Fathartaigh, M.Ó. Pursuing added value in the Irish agri-food sector: An application of the Global Value Chain methodology. Proc. Food Syst. Dyn. 2016. [CrossRef]

4. Donnellan, T.; Moran, B.; Lennon, J.; Dillon, E. Teagasc National Farm Survey 2019 Preliminary Results; Agriculture and Food Development Authority: Carlow, Ireland, 2020; ISBN 1-84170-664-7.

5. Dillon, E.; Moran, B.; Lennon, J.; Donnellan, T. National Farm Survey 2017; Agriculture and Food Development Authority: Carlow, Ireland, 2018; ISBN 978-1-84170-648-1.

6. Hanrahan, K. Transparency in Beef Markets in Ireland; Agriculture and Food Development Authority: Carlow, Ireland, 2018.

7. Renwick, A. From Blockades to Supply Chain Integration: Challenges of Co-Ordination in the Agrifood Sector; Australian Agricultural \& Resource Economics Society: Melbourne, Australia, 2015.

8. Smith, B.; Moran, T. Annual Report 2009; Department of Agriculture, Food and the Marine: Dublin, Ireland, 2010.

9. Sexton, R.J. Market Power, Misconceptions, and Modern Agricultural Markets. Am. J. Agric. Econ. 2013, 95, 209-219. [CrossRef]

10. Landes, W.M.; Posner, R.A. Market Power in Antitrust Cases. Harv. Law Rev. 1981, 94, 937-996. [CrossRef]

11. Mason, E.S. Price and production policies of large-scale enterprise. Am. Econ. Rev. 1939, 29, 61-74.

12. Bain, J.S. Relation of profit rate to industry concentration: American manufacturing, 1936-1940. Q. J. Econ. 1951, 65, 293-324. [CrossRef]

13. Bresnahan, T.F. Empirical studies of industries with market power. Handb. Ind. Organ. 1989, 2, 1011-1057.

14. Applebaum, E. The Estimation of the Degree of Oligopoly Power. J. Econom. 1982, 19, 287-299. [CrossRef]

15. Bonanno, A.; Russo, C.; Menapace, L. Market power and bargaining in agrifood markets: A review of emerging topics and tools. Agribusiness 2018, 34, 6-23. [CrossRef]

16. Perekhozhuk, O.; Glauben, T.; Grings, M.; Teuber, R. Approaches and methods for the econometric analysis of market power: A survey and empirical comparison. J. Econ. Surv. 2017, 31, 303-325. [CrossRef]

17. Schroeter, J.R. Estimating the degree of market power in the beef packing industry. Rev. Econ. Stat. 1988, 70, 158-162. [CrossRef]

18. Azzam, A.M. Measuring market power and cost-efficiency effects of industrial concentration. J. Ind. Econ. 1997, 45, 377-386. [CrossRef]

19. Paul, C.J.M. Market and cost structure in the US beef packing industry: A plant-level analysis. Am. J. Agric. Econ. 2001, 83, 64-76. [CrossRef]

20. Panagiotou, D.; Stavrakoudis, A. A Stochastic Production Frontier Estimator of the Degree of Oligopsony Power in the U.S. Cattle Industry. J. Ind. Compet. Trade 2017, 17, 121-133. [CrossRef]

21. Ji, I.; Chung, C.; Lee, J. Measuring Oligopsony Power in the US Cattle Procurement Market: Packer Concentration, Cattle Cycle, and Seasonality. Agribusiness 2017, 33, 16-29. [CrossRef]

22. Rude, J.; Harrison, D.; Carlberg, J. Market Power in Canadian Beef Packing. Can. J. Agric. Econ. 2011, 59, 321-336. [CrossRef]

23. Koontz, S.R.; Garcia, P. Meat-packer conduct in fed cattle pricing: Multiple-market oligopsony power. J. Agric. Resour. Econ. 1997, 22, 87-103. [CrossRef]

24. Muth, M.K.; Wohlgenant, M.K. Measuring the Degree of Oligopsony Power in the Beef Packing Industry in the Absence of Marketing Input Quantity Data. J. Agric. Resour. Econ. 1999, 24, $299-312$.

25. Yamaura, K.; Featherstone, A.M. Estimating the effect of monopsony power on elasticity estimates. Appl. Econ. 2016, 48, 179-189. [CrossRef]

26. Azzam, A.; Andersson, H. Measuring price effects of concentration in mixed oligopoly: An application to the Swedish beefslaughter industry. J. Ind. Compet. Trade 2008, 8, 21-31. [CrossRef]

27. Wohlgenant, M.K. Competition in the US meatpacking industry. Annu. Rev. Resour. Econ. 2013, 5, 1-12. [CrossRef]

28. Boyer, C.N.; Brorsen, B.W. Changes in Beef packers' market power after the livestock mandatory price reporting act: An agent-based auction. Am. J. Agric. Econ. 2013, 95, 859-876. [CrossRef]

29. Surathkal, P.; Chung, C. Effects of packers' inventory and market power on price adjustments in the U.S. beef industry. Appl. Econ. 2019, 51, 5076-5089. [CrossRef]

30. Chung, C.; Park, S.; Lee, J. Estimating bilateral market power of processors and retailers in the U.S. beef industry. Agribusiness 2018, 34, 771-792. [CrossRef]

31. Panagiotou, D. Market Power Effects of the Livestock Mandatory Reporting Act in the U.S. Meat Industry: A Stochastic Frontier Approach Under Uncertainty. J. Ind. Compet. Trade 2019, 19, 103-122. [CrossRef]

32. Panagiotou, D.; Stavrakoudis, A. A Stochastic Frontier Analysis Approach for Estimating Market Power in the Major US Meat Export Markets. J. Ind. Compet. Trade 2020, 20, 569-586. [CrossRef]

33. Cai, X.; Stiegert, K.W.; Koontz, S.R. Oligopsony fed cattle pricing: Did mandatory price reporting increase meatpacker market power? Appl. Econ. Perspect. Policy 2011, 33, 606-622. [CrossRef]

34. Riordan, N.; Cowan, C.; McCarthy, M. Safety of Irish beef-Concerns, awareness and knowledge of Irish consumers. J. Food Saf. 2002, 22, 1-15. [CrossRef] 
35. McCarthy, M.; Henson, S. Perceived risk and risk reduction strategies in the choice of beef by Irish consumers. Food Qual. Prefer. 2005, 16, 435-445. [CrossRef]

36. McCarthy, M.; de Boer, M.; O’Reilly, S.; Cotter, L. Factors influencing intention to purchase beef in the Irish market. Meat Sci. 2003, 65, 1071-1083. [CrossRef]

37. Cillero, M.M.; Thorne, F.; Wallace, M.; Breen, J.; Hennessy, T. The Effects of Direct Payments on Technical Efficiency of Irish Beef Farms: A Stochastic Frontier Analysis. J. Agric. Econ. 2018, 69, 669-687. [CrossRef]

38. Binfield, J.C.R.; Hennessy, T.C. Beef sector re-structuring after Agenda 2000: An Irish example. Food Policy 2001, 26, 281-295. [CrossRef]

39. Crosson, P.; O'Kiely, P.; O'Mara, F.P.; Wallace, M. The development of a mathematical model to investigate Irish beef production systems. Agric. Syst. 2006, 89, 349-370. [CrossRef]

40. Teresa, H.; Aine, M.W.; Olive, M.; Carol, P.; Maeve, H. Co-Operation among Irish Beef Farmers: Current Perspectives and Future Prospects in the Context of New Producer Organisation (PO) Legislation. Sustainability 2018, 10, 4085. [CrossRef]

41. Fischer, C.; Hartmann, M. Agri-Food Chain Relationships; CABI: Wallingford, UK, 2010; ISBN 1845936434.

42. Power, J. An Independent Assessment of the Irish Beef Industry; Irish Farmers' Association: Dublin, Ireland, 2020.

43. Zheng, X.; Vukina, T. Do alternative marketing arrangements increase pork packers' market power? Am. J. Agric. Econ. 2009, 91, 250-263. [CrossRef]

44. Burke, J. Teagasc Beef Manual; Department of Agriculture, Food and the Marine: Dublin, Ireland, 2016; Section 1, Chapter 4, pp. 3-26.

45. Ferriello, I. Annual Report and Financial Statements 2012; Health Service Executive: Dublin, Ireland, 2013; pp. 1-120.

46. Zsohar, P. Short introduction to the generalized method of moments. Hung. Stat. Rev. 2012, 16, 150-170.

47. Quagrainie, K.; Unterschultz, J.; Veeman, M.; Jeffrey, S. Testing for processor market power in the markets for cattle and hogs in Canada. Can. J. Agric. Econ. Can. Agroecon. 2003, 51, 397-411. [CrossRef]

48. Marsh, J.M. Impacts of declining US retail beef demand on farm-level beef prices and production. Am. J. Agric. Econ. 2003, 85, 902-913. [CrossRef]

49. Crosson, P.; Finneran, E.; McGee, M. Drivers of Profit for Beef Production Systems; Department of Agriculture, Food and the Marine: Dublin, Ireland, 2016; Section 2; pp. 29-84.

50. Crespi, J.M.; Xia, T.; Jones, R. Market power and the cattle cycle. Am. J. Agric. Econ. 2010, 92, 685-697. [CrossRef]

51. Stiegert, K.W.; Azzam, A.; Brorsen, B.W. Markdown Pricing and Cattle Supply in the Beef Packing Industry. Am. J. Agric. Econ. 1993, 75, 549-558. [CrossRef]

52. Love, A. An Investigation of the Effects of BSE on the Canadian Cattle and Beef Markets; Report; Competition Bureau Canada: Montreal, QC, Canada, 2005.

53. Azzam, A.M.; Pagoulatos, E. Testing oligopolistic and oligopsonistic behaviour: An application to the us meat-packing industry. J. Agric. Econ. 1990, 41, 362-370. [CrossRef]

54. Azzam, A.; Park, T. Testing for switching market conduct. Appl. Econ. 1993, 25, 795-800. [CrossRef]

55. Church, J.; Gordon, D. Market Power in the Alberta Red Meat Packing Industry; IAPR Technical Paper 07004; Institute for Advanced Policy Research, University of Calgary: Calgary, AB Canada, 2007.

56. Chen, Y.; Yu, X. Do subsidies cause a less competitive milk market in China? Agric. Econ. 2019, 50, 303-314. [CrossRef] 